\title{
molecules
}

ISSN 1420-3049

http://www.mdpi.org

Full Paper

\section{Synthesis and Photochemistry of 1-Iodocyclohexene: Influence of Ultrasound on Ionic vs. Radical Behaviour ${ }^{\dagger}$}

\author{
Marika Blaskovicova *, Anton Gaplovsky and Jaroslav Blasko \\ Institute of Chemistry, Faculty of Natural Sciences, Comenius University, Mlynska dolina CH-2, SK- \\ 842 15, Bratislava, Slovakia; Tel.: (+421) 260296 319, Fax.: (+421) 260296 684; E-mails: \\ gaplovsky@fns.uniba.sk; blasko@fns.uniba.sk
}

* Author to whom correspondence should be addressed, e-mail: noskova@fns.uniba.sk

${ }^{\dagger}$ Paper presented at ECSOC-10, 1-30 November 2006

Received: 14 December 2006; in revised form: 24 January 2007 / Accepted: 25 January 2007 / Published: 16 February 2007

\begin{abstract}
Simultaneous application of UV light and ultrasonic irradiation to a reaction mixture containing 1-iodocyclohexene is reported. The irradiation of 1-iodocyclohexene in methanol was carried out with or without addition of zinc. The effect of ultrasound or mechanical stirring on this solid-liquid system was also compared. The irradiation of 1iodocyclohexene in methanol in the presence of zinc increases the yield of the nucleophilic trapping product, compared with the yield after irradiation in the absence of zinc. The photodegradation of 1-iodocyclohexene was slightly accelerated after addition of zinc. A rapid formation of radical product was accompanied by substantial decrease of 1-iodocyclohexene after application of ultrasound and irradiation without the zinc. The ultrasound significantly affects the photobehaviour of this reaction, predominantly its radical route. The joint application of ultrasound and zinc contributes positively to the production of radical and ionic products. The sonochemical stirring is more effective than mechanical stirring.
\end{abstract}

Keywords: Ultrasound, photochemistry, 1-iodocyclohexene. 


\section{Introduction}

Alkyl halides exhibit competing radical and ionic photobehaviours [1]. Iodides give predominantly ionic products. The irradiation process involves the initial homolytic cleavage of the carbon-halogen bond, followed by electron transfer within a radical pair to generate an ion pair. Irradiation of alkyl halides is a convenient method for generation of carbocations. The corresponding vinyl cations are generated by irradiation of vinyl iodides. The products of photochemical reactions depend on the light intensity, as well as on effectiveness of the reaction mixture stirring [2]. The application of the ultrasound, especially in heterogeneous reactions, causes a mechanical effect responsible for the mass transfer, that is, a thorough stirring of the reaction mixture, as well as the activation of the surface of the solid reagents present [3-5]. The second effect of ultrasound, the most pronounced one in homogenous reactions, is caused by the high temperatures (up to $5000 \mathrm{~K}$ ) and high pressures (up to $400 \mathrm{~atm}$ ), which are involved in the collapsing bubbles (cavities) in the ultrasound field [3-5]. The main goal of this work was to examine simultaneous sonication and UV irradiation of 1-iodocyclohexene in methanol in absence/presence of zinc as iodine scavenger.

\section{Results and Discussion}

The 1-iodocyclohexene $\mathbf{3}$ was prepared from ketone $\mathbf{1}$ by using some modifications of the general method of Pross and Sternhell [6] (Scheme 1).

Scheme 1. Synthesis of 1-iodocyclohexene.

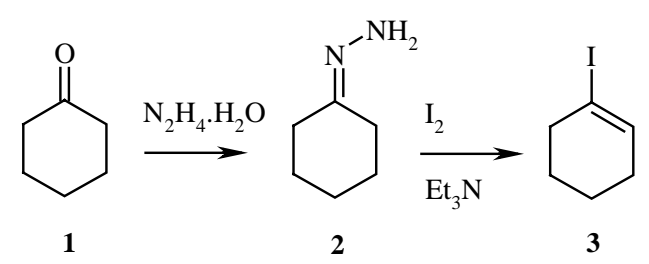

Figure 1. Irradiation of 1-iodocyclohexene in methanol $\left(\lambda_{\mathrm{IR}}=254 \mathrm{~nm} ; \mathrm{t}_{\mathrm{IR}}=60 \mathrm{~min}\right)$ monitored by GC.

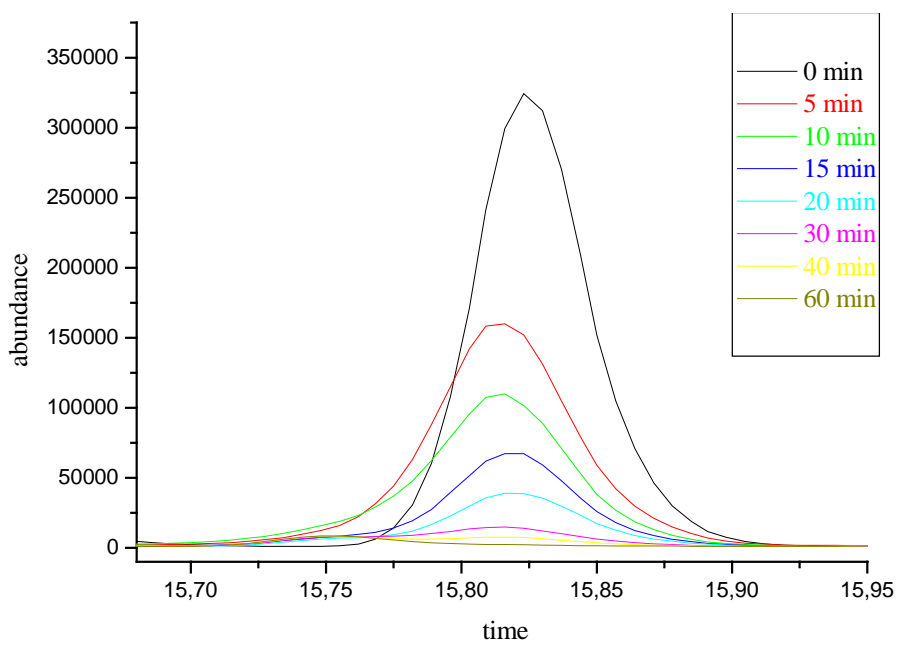


Irradiation of 1-iodocyclohexene (3) in methanol $(\lambda=254 \mathrm{~nm}$, Figure 1) afforded a mixture of the dimethyl ketal 6, enol ether 5 and cycloalkene 4 [7] (Scheme 2). Product 6 arises from an acidcatalyzed addition of methanol to the nucleophilic trapping product $\mathbf{5}$. Product $\mathbf{4}$ is a radical-derived reduction product (Table 1 , entry $\mathbf{A}$ ).

\section{Scheme 2.}

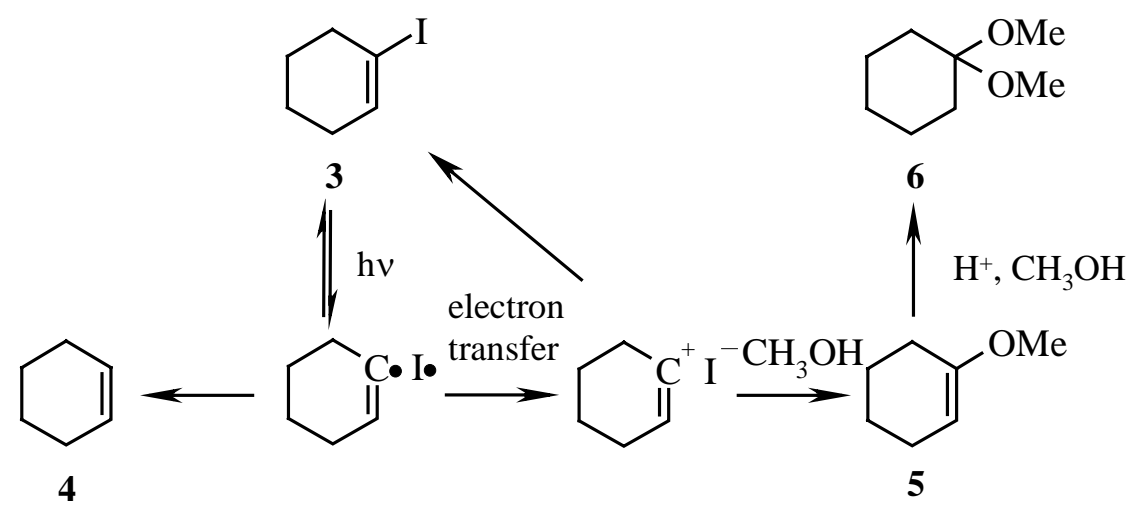

Table 1. Irradiation of 1-iodocyclohexene in methanol.

\begin{tabular}{|c|c|c|c|c|c|}
\hline Conditions & time & $\begin{array}{c}3 \\
\text { (min) }\end{array}$ & $\begin{array}{c}\mathbf{6} \\
\mathbf{( \% )}\end{array}$ & $\begin{array}{c}\mathbf{5} \\
\mathbf{( \% )}\end{array}$ & $\begin{array}{c}\mathbf{4} \\
(\mathbf{\%})\end{array}$ \\
\hline $\mathbf{( \% )}$ \\
\hline A & 40 & 33 & 23 & 18 & 26 \\
B & 40 & 10 & 23 & 25 & 42 \\
C & 40 & 24 & 20 & 35 & 22 \\
D & 40 & 4 & 15 & 41 & 40 \\
\hline
\end{tabular}
A - irradiation
B - irradiation and ultrasound
C - irradiation in presence of zinc and mechanical agitation
D - ultrasound and irradiation in presence of zinc

A rapid formation of $\mathbf{4}$, accompanied by a great decrease in the amount of $\mathbf{3}$ formed was observed after application of ultrasound (Table 1 , entry $\mathbf{B}$ ). The ultrasound significantly affects photobehaviour of this reaction, predominantly the radical route. With mechanical stirring in the presence of zinc as an acid scavenger, the enol ether $\mathbf{5}$ was mainly obtained (Table 1, entry $\mathbf{C}$ ). Ultrasound and irradiation in the presence of zinc caused rapid photodegradation of $\mathbf{3}$ and an increase in the ratio of the radical products 4D and 4C. The results obtained in our study showed that ultrasound affects the photobehaviour of 1-iodo-cyclohexene in methanol. Ultrasound markedly influenced the lifetime of the radical pair resulting from initial homolytic cleavage of the carbon-halogen bond. An increase of radical product $\mathbf{4}$ was observed. The ultrasound caused rapid photodegradation of starting iodide $\mathbf{3}$ (Table 1 entries A,B). The irradiation of 1-iodocyclohexene in methanol in presence of zinc increases the yield of $\mathbf{5}$ compared with the yield after irradiation without zinc. The sonochemistry of zinc powder was investigated a few years ago [8]. Ultrasound creates acoustic cavitation in liquids. In the presence of fine powders, shockwaves and turbulent flow from cavitation result in interparticle 
collisions of solids. Such collisions occur with enough force to cause changes in the morphology of powders. After application of ultrasound on zinc powder, dramatic changes in particle morphology were observed. Whereas the mechanical aggitation keeps zinc particles smooth (Figure 2), the ultrasound makes the particles rough and grainy (Figure 3). The particle fragmentation improves the mass transport. Ultrasound and zinc positively contribute to the production of $\mathbf{4}$ and $\mathbf{5}$. The rapid photodegradation of $\mathbf{3}$ was also observed. Mechanical stirring is more or less local, being most effective near the stirrer, but not so effective in the close proximity of the reactor walls. The sonochemical stirring is evenly distributed over the entire reaction volume, as cavities are formed and implode throughout the reaction mixture [4].

Figure 2. Zn powder, mechanical stirring.
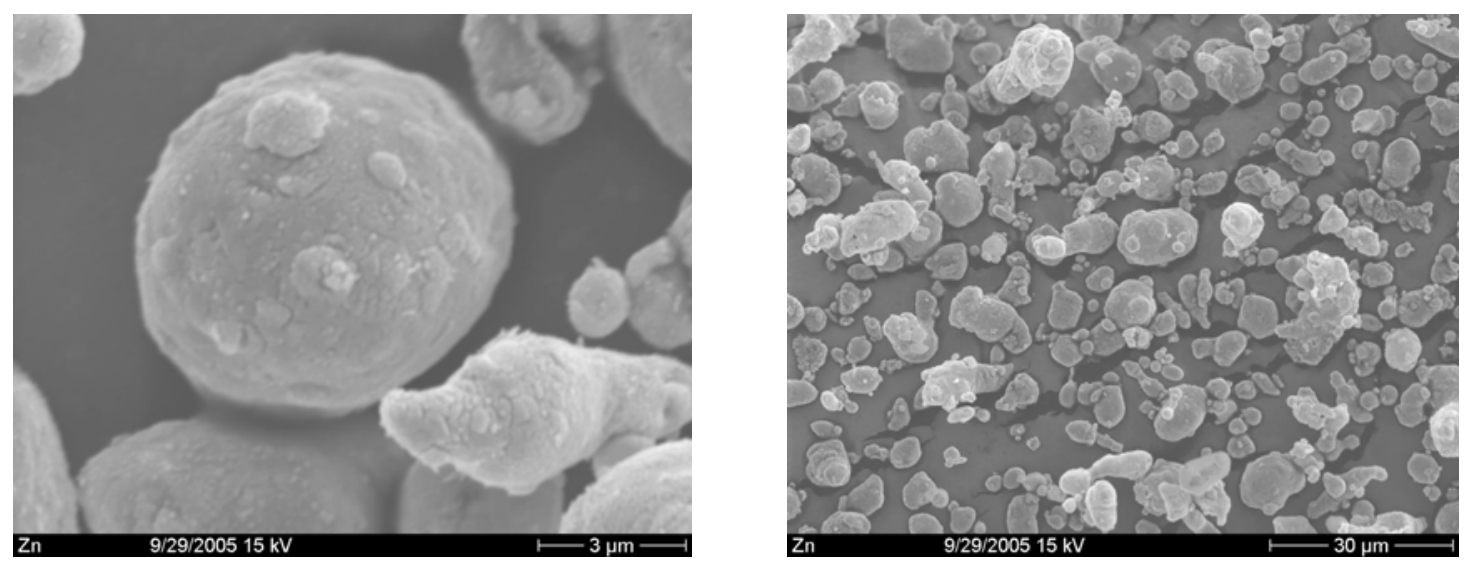

Figure 3. Zn powder, ultrasound.
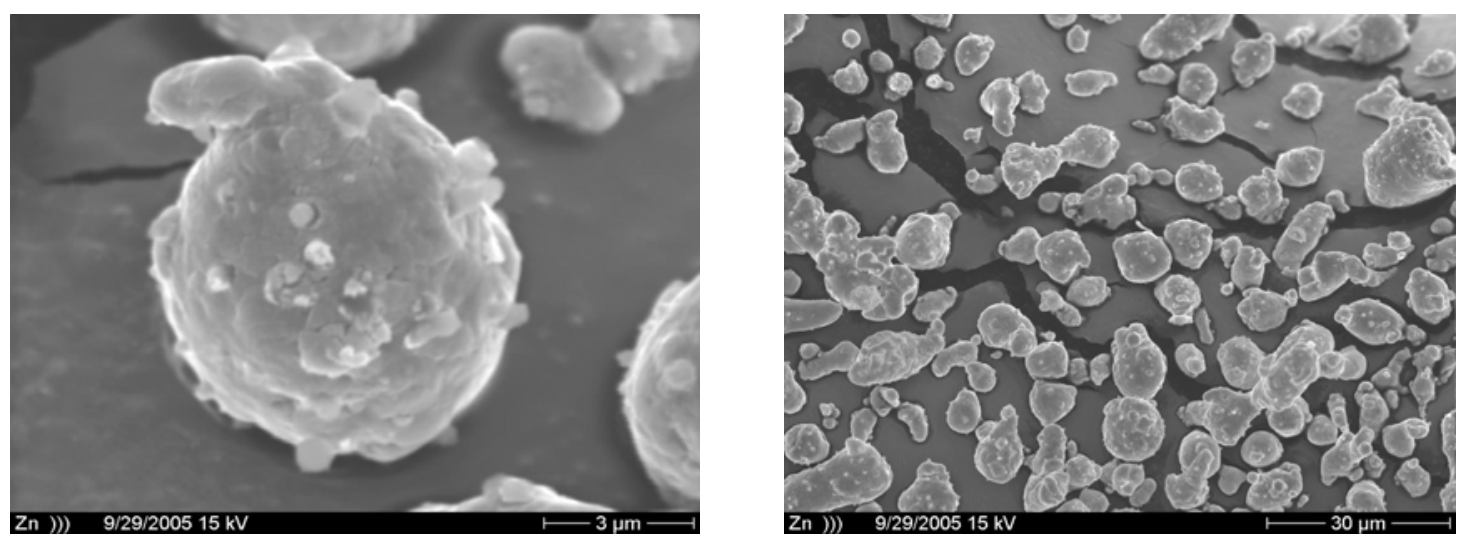

\section{Conclusions}

From the results of this work it follows that ultrasound significantly affects photobehaviour of 1iodocyclohexene predominantly its the radical route. Enhancements due to ultrasound may be attributed to its chemical or mechanical effects, or to both simultaneously. The chemical effects of ultrasound are due to the implosion of microbubbles, generating free-radicals with a great propensity 
for reaction. Mechanical effects are caused by shock waves formed during symmetric cavitation, or by microjects formed during asymmetric cavitation.

\section{Experimental}

\section{General}

Gas-chromatographic analyses were performed on an Agilent 6890N instrument using a HP-1 capillary column (50 m x $0.32 \mathrm{~mm}$ ID with $1.05 \mu \mathrm{m}$ film thickness). Cyclohexene was used as an internal hydrocarbon standard. Proton NMR spectra were determined in chloroform- $d$ on a Varian Mercury Plus $300 \mathrm{MHz}$ spectrometer. Mass spectra were obtained by using a MSD-Agilent 5973 Network spectrometer.

Preparation of 1-iodocyclohexene (3).

The iodide $\mathbf{3}$ was prepared from the corresponding ketone $\mathbf{1}$ by using some modifications of general method of Pross and Sternhell [6]. Hydrazine hydrate $(40.8 \mathrm{~mL}, 0.84 \mathrm{~mol})$ was placed into round-bottomed flask equipped with a magnetic stirrer, condenser and an addition funnel. A solution of cyclohexanone $(6.4 \mathrm{~mL}, 61.5 \mathrm{mmol})$ in absolute methanol $(35 \mathrm{~mL})$ was added very slowly (ca. 3 drops per min !!!) to the hydrazine hydrate with vigorous stirring. When the addition was complete the reaction mixture was refluxed for $1 \mathrm{~h}$ and then cooled to room temperature. The methanol was evaporated and reaction mixture was washed with chloroform, aqueous sodium chloride and dried over anhydrous sodium sulphate. After filtration and evaporation of chloroform $6.3 \mathrm{~g}$ (91\%) of hydrazone 2 was obtained. ${ }^{1} \mathrm{H}-\mathrm{NMR}: 4.88$ (s, $2 \mathrm{H},-\mathrm{NH}_{2}$ ), 2.28 (m, 2H, C1), 2.33 (m, 2H, C5), 2.23 (m, 4H, C2, C4), $1.73(\mathrm{~m}, 2 \mathrm{H}, \mathrm{C} 3)$. Iodine $(27.4 \mathrm{~g}, 0.11 \mathrm{~mol})$ in dry ether $(170.4 \mathrm{~mL})$ was added dropwise at room temperature to a stirred solution of triethylamine $(41.6 \mathrm{~mL}, 0.29 \mathrm{~mol})$ and hydrazone 2 (6 g, $0.05 \mathrm{~mol})$ in dry ether $(18.1 \mathrm{~mL})$. The colour of the reaction mixture changed from yellow to brown after addition of the iodine solution. The reaction was instantaneous, but stirring was continued for a further $20 \mathrm{~min}$. The reaction mixture was diluted by adding dry ether $(150 \mathrm{~mL})$ and washed successively with saturated aqueous sodium sulphite, $3 \mathrm{~N} \mathrm{HCl}$, saturated aqueous sodium bicarbonate and aqueous sodium chloride. The organic layer was then dried over sodium sulphate and evaporated to give crude product 3 (1.37 g, 13\%) which was purified by chromatography (silica gel, 100-250 mesh, petroleum ether bp 40-60 ${ }^{\circ} \mathrm{C}$ ). ${ }^{1} \mathrm{H}-\mathrm{NMR}: 6.33$ (sept, $1 \mathrm{H}, \mathrm{CH}$ ), 2.5 (m, 2H, C6), 2.1 (m, 2H, C3), 1.7 (m, 4H, C2, C6).

\section{Ultrasonic irradiations.}

A photochemical reactor allowing simultaneous ultrasound irradiation was used. A sandwich piezoelectric transducer $\left(50 \mathrm{~W}, 20 \mathrm{kHz}\right.$, intensity $\approx 16 \mathrm{~W} . \mathrm{cm}^{-2}$ ) was attached with an epoxy resin to the bottom of a normal photochemical reactor with internal water-cooling (50 mm diameter, $40 \mathrm{~mL}$ volume). Irradiations of 3 in methanol (c $\left.=1.63 \times 10^{-3} \mathrm{~mol} / \mathrm{L}\right)$ were carried out with a $4 \mathrm{~W}(254 \mathrm{~nm})$ low pressure mercury lamp. Durring irradiation, the solution was flushed with argon. 


\section{References}

1. McNeely, S.A.; Kropp, P.J. Photochemistry of Alkyl Halides. 3. Generation of Vinyl Cations. $J$. Am. Chem. Soc. 1976, 98, 4319-4320.

2. Gaplovsky, A.; Donovalova, J.; Toma, S.; Hrnciar, P. Fotochemický reaktor s ultrazvukovým miešaním. Vplyv ultrazvuku na priebeh fotochemických reakcií. Chem. Listy 1986, 80, 989-993.

3. Gaplovsky, A.; Donovalova, J.; Toma, S.; Kubinec, R. Ultrasound effects on photochemical reactions, Part 1: photochemical reactions of ketones with alkenes. Ultrason. Sonochem. 1997, 4, 109-115.

4. Gaplovsky, A.; Donovalova, J.; Toma, S.; Kubinec, R. Ultrasound effects on photochemical reactions 2. A study of ultrasound effects on some monomolecular and bimolecular reactions. $J$. Photochem. Photobiol. A: Chem. 1998, 115, 13-19.

5. Toma, S.; Gaplovsky, A.; Luche, L.J. The effect of ultrasound on photochemical reactions. Ultrason. Sonochem. 2001, 8, 201-207.

6. Pross, A.; Sternhell, S. Oxidation of hydrazones with iodine in the presence of base. Aust. J. Chem. 1970, 23, 989-1003.

7. Kropp, P.J.; McNeely, S.A.; Davis, R.D. Photochemistry of Alkyl Halides. 10. Vinyl Halides and Vinylidene Dihalides. J. Am. Chem. Soc. 1983, 105, 6907-6915.

8. Suslick, K.S.; Doktycz S.J. Sonochemistry of Zn Powder. J. Am. Chem. Soc. 1989, 111, 23422344.

Sample Availability: Compound samples are not available.

(C) 2007 by MDPI (http://www.mdpi.org). Reproduction is permitted for noncommercial purposes. 